\title{
INTERAÇÃO ESCOLA-COMUNIDADE EM PROGRAMAS/PROJETOS NAS ÁREAS DE EDUCAÇÃO, DIREITOS HUMANOS E DESENVOLVIMENTO SOCIAL
}

\author{
Graziela Lionetti de FEO $^{1}$ \\ Universidade Nove de Julho/Uninove/SP \\ grazilionetti@hotmail.com \\ Roberta STANGHERLIM ${ }^{2}$ \\ Universidade Nove de Julho/Uninove/SP \\ roberta.stan@hotmail.com
}

Resumo: Esta pesquisa busca mapear Programas/Projetos dos governos federal, estadual e municipal de São Paulo que apoiam a implementação de experiências de interação da escola com a comunidade, conforme previsto no Plano Nacional de Educação em Direitos Humanos. Foram levantadas informações nos sites do Ministério da Educação e da Secretaria dos Direitos Humanos, das Secretarias de Educação e de Desenvolvimento Social, ambas dos governos do Estado e do Município de São Paulo. Conclui-se que poucos programas visam diretamente os objetivos desta pesquisa, e a maior parte se aplica indiretamente, na medida em que alguns deles se destinam às famílias e às crianças de 0 a 6 anos de idade, com propostas para a garantia da rede de proteção social.

Palavras-chave: Crianças de 0 a 6 anos. Escola-Comunidade. Plano Nacional de Educação em Direitos Humanos.

1 Estudante do curso de Pedagogia da Universidade Nove de Julho (UNINOVE). Bolsista de IC PIBIC/CNPq.

2 Doutora em Educação: Psicologia da Educação pela PUC/SP. Professora no Mestrado profissional em Gestão e Práticas Educacionais da Universidade Nove de Julho. 


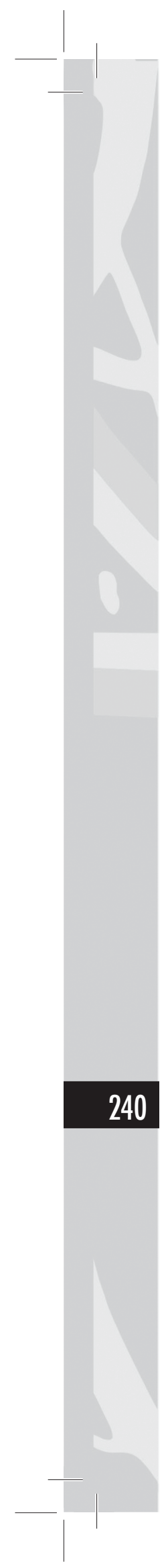

\begin{abstract}
Thispaperaims to map programs/projects offederal and state governments and São Paulo city which support the implementation of interaction experiences with the school community, as envisaged in the National Plan for Human Rights Education. We surveyed the websites of the Ministry of Education, Department of Human Rights and the Departments of Education and Social Development, both from State of São Paulo including the city of São Paulo. We concluded that few programs were directly targeting the objectives of this research, since most of them indirectly apply, and some of them are designed for families and children from 0 up to 6 years old, with proposals for ensuring network social protection.
\end{abstract}

Keywords: Children 0-6 years. School-Community. National Plan for Human Rights Education.

\title{
Introdução
}

Esta pesquisa está vinculada aos trabalhos do Grupo de Pesquisa Práticas Político-Sociais (GRUPESC), do Programa de Mestrado Profissional em Gestão e Práticas Educacionais (PROGEPE) da UNINOVE. E pretende contribuir com os estudos na área da educação, enfocando uma dentre as 27 ações programáticas do Plano Nacional de Educação em Direitos Humanos (PNEDH) para o eixo da Educação Básica, como apontado à página 34 desse documento, a ação de número 12: "apoiar a implementação de experiências de interação da escola com a comunidade, que contribuam para a formação da cidadania em uma perspectiva crítica dos direitos humanos".

O objetivo da investigação foi mapear, por meio de sites oficiais do governo federal e dos governos do estado e do município de São Paulo, a existência de programas e projetos que apresentem, em seu escopo, propostas destinadas a atender a ação programática de número 12 do eixo "Educação Básica" do PNDEH e, mais especificamente, identificar os enfoques atribuídos àqueles programas e projetos voltados às escolas de Educação Infantil, que atendem crianças de 0 a 6 anos de idade.

Desde 1948, poucos anos após a Segunda Guerra Mundial e sob seu impacto, a Declaração Universal dos Direitos Humanos 
da Organização das Nações Unidas (ONU) tem desencadeado a produção de diversos instrumentos e mecanismos de ordenamento jurídico nos países signatários, na perspectiva de se criarem sistemas (internacionais e nacionais) de proteção dos direitos humanos.

A concepção contemporânea de direitos humanos introduzida por esse documento internacional foi reiterada pela Declaração dos Direitos Humanos de Viena, de 1993. Tal concepção estabelece os princípios da universalidade e da indivisibilidade, os quais correspondem, respectivamente, à ideia da extensão universal dos direitos humanos, uma vez que a condição de sujeito é requisito único para a titularidade de direitos; e porque a garantia dos direitos civis e políticos é condição para que sejam assegurados os direitos sociais, econômicos e culturais. A violação de um desses direitos implica a violação dos demais (PIOVESAN, 2008)

No Brasil, o debate sobre os direitos humanos vem ganhando mais espaço e relevância nas décadas de 1980 e 1990, período em que a Constituição Federal de 1988 foi sancionada, formalizando o Estado Democrático de Direito e reconhecendo a dignidade humana como direito de todo cidadão e cidadã.

Visando o fortalecimento do processo de reconstrução democrática do país, a sociedade civil organizada mobilizou-se para a elaboração de propostas em defesa da garantia de direitos em diversas instâncias. Os movimentos da infância e da educação obtiveram conquistas expressivas com a promulgação do Estatuto da Criança e do Adolescente (ECA, Lei n. 8.069/90), em 1990, e com a Lei de Diretrizes e Bases da Educação (LDBEN, Lei 9394/96), seis anos depois. O ECA estabeleceu a proteção integral à criança e ao adolescente, por meio de direitos fundamentais: à vida e à saúde; à liberdade, ao respeito e à dignidade; à convivência familiar e comunitária; à educação, à cultura, ao esporte e ao lazer; à profissionalização e à proteção no trabalho. A LDBEN prevê, em seu artigo $2^{\circ}$, "a educação como um dever da família e do Estado, inspirado nos princípios de liberdade e nos ideais de solidariedade humana, e tem por finalidade o pleno desenvolvimento do educando, seu preparo para a cidadania e sua qualificação para o trabalho" (BRASIL, 1996).

Mais de uma década após a instituição do ECA e da LDBEN, 
em 2003, foi lançado o Plano Nacional de Educação em Direitos Humanos (PNEDH), cuja implementação

visa, sobretudo, difundir a cultura de direitos humanos no país. Essa ação prevê a disseminação de valores solidários, cooperativos e de justiça social, uma vez que o processo de democratização requer o fortalecimento da sociedade civil, a fim de que seja capaz de identificar anseios e demandas, transformando-as em conquistas que só serão efetivadas, de fato, na medida em que forem incorporadas pelo Estado Brasileiro como políticas públicas universais. (PNEDH, 2008, p. 26)

Viola (2010), ao refletir sobre as políticas de educação em direitos humanos, afirma a indispensabilidade da educação na formação em e para os direitos humanos. Nas palavras do autor,

Compreender a democracia e os direitos humanos como uma construção que se faz ao longo da história, e que tem diante de si o futuro, pressupõe atribuir à educação um lugar indispensável de formação em e para os direitos humanos, na medida em que, através do ato educativo, pode-se se não transformar a sociedade, construir a cultura indispensável para essa transformação. (VIOLA, 2010, p. 22)

No PNEDH (2008, p. 25), "a educação em direitos humanos é compreendida como um processo sistemático e multidimensional que orienta a formação do sujeito de direitos". Nessa linha de raciocínio, o Plano abrange cinco eixos, com suas respectivas diretrizes em termos de concepções, princípios e ações programáticas. Os eixos correspondemà:Educação Básica;Educação Superior; Educação não-formal; Educação dos profissionais dos sistemas de justiça e segurança; Educação e mídia. Nele também são estabelecidas linhas gerais de ação: desenvolvimento normativo e institucional; produção de informação e conhecimento; realização de parcerias e intercâmbios internacionais; produção e divulgação 
de materiais; formação e capacitação de profissionais; gestão de programas e projetos; avaliação e monitoramento.

Uma política de educação em direitos humanos impõe o fortalecimento da constituição da rede de proteção integral, conforme preconiza o ECA. Nessa perspectiva, supõe-se que os programas e projetos alcancem dimensões inter-setoriais com práticas político-sociais que valorizem o pleno desenvolvimento de crianças e adolescentes.

Sendo assim, os objetivos específicos desta pesquisa foram: a) levantar projetos e programas do governo federal e dos governos do estado e do município de São Paulo que contemplem a ação programática de número 12 referente ao apoio à implementação de experiências de interação da escola com a comunidade, conforme estabelecida no eixo Educação Básica do PNEDH; b) selecionar, dentre os projetos levantados, aqueles se destinam à primeira etapa da Educação Básica, ou seja, ao segmento da Educação Infantil; c) identificar objetivos, metas, público envolvido e resultados esperados e/ou alcançados por esses programas e projetos.

Para tanto, a metodologia utilizada foi de base documental e bibliográfica, de caráter exploratório, desenvolvida nas seguintes etapas: $1^{\text {a }}$ etapa - leitura e identificação dos conteúdos disponíveis nos sites oficiais do governo federal (Ministério da Educação e Secretaria de Direitos Humanos), do estado paulista (Secretarias da Educação e do Desenvolvimento Social) e do município de São Paulo (Secretaria de Educação e de Assistência Social) para na 2a etapa elaborar relatório preliminar com os dados quantitativos e preparar planilhas para elaboração das próximas duas fases. A $3^{\text {a }}$ etapa consistiu na elaboração de quadros com informações que permitissem categorizar os programas e projetos selecionados, tendo em vista a possibilidade de na $4^{\text {a }}$ etapa analisar e interpretar os dados obtidos. Por fim, na última etapa foi elaborado artigo com os resultados para divulgação científica.

Levando em consideração os sites investigados tanto no âmbito da Educação quanto no âmbito do Desenvolvimento Social, nos níveis federal, estadual (SP) e municipal (SP), obteve-se o total de 13 programas/projetos de governo com características que se aproximaram ao objetivo geral delineado para esta pesquisa, tendo

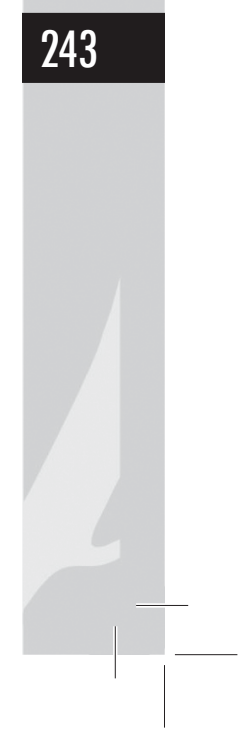




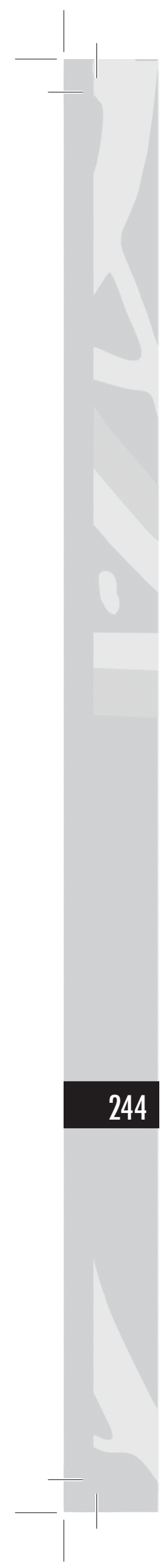

em vista a descrição dos objetivos e do público envolvido. Não foram encontrados explicitados as metas e os resultados esperados e/ou alcançados.

Foram poucos os programas/projetos que apresentam como objetivo específico apoiar a implementação de experiências de interação da escola com a comunidade, conforme descrito no eixo "Educação Básica" do PNEDH, distanciando-se ainda mais quando se trata de escolas da Educação Infantil. Os resultados apresentados a seguir evidenciam que a maior parte dos programas/ projetos atende indiretamente a esse objetivo. Assim, diante dos conteúdos levantados foi considerado "objetivo atendido de forma direta" quando se identificavam programas/projetos da área da Educação e do Desenvolvimento Social que enfocam ações voltadas para o fortalecimento da rede de proteção social à criança, fundamentalmente aqueles que abrangem o público de crianças de 0 a 6 anos, mas que não necessariamente estão direcionados para as escolas de Educação infantil. E "objetivo atendido de forma indireta", os Programas/Projetos cujos conteúdos não indicavam direta e explicitamente o objetivo (experiências de interação escolacomunidade) e o público (crianças de 0 a 6 anos).

\section{Programas/projetos na área da educação}

A distribuição dos programas/projetos corresponde à área da Educação levantada nos sites oficiais dos governos federal (Ministério da Educação e Cultura), estadual de São Paulo (Secretaria Estadual da Educação) e municipal de São Paulo (Secretaria Municipal de Educação).

A Tabela 1 a seguir expõe a quantidade de nove programas/ projetos, sendo quatro com objetivos que podem ser considerados de apoio à implementação de experiências de interação escolacomunidade e cinco considerados indiretos, uma vez que apresentam objetivos que possibilitam supor abranger propostas de fortalecimento da rede de proteção social de crianças entre zero e seis anos de idade, mas não necessariamente explicitam ações voltadas às escolas de educação básica, especialmente àquelas de educação infantil. 
Tabela 1: Programas/projetos na área da Educação

\begin{tabular}{|c|c|c|c|c|}
\hline & $\begin{array}{l}\text { QUANTIDADE } \\
\text { TOTAL DE } \\
\text { PROJETOS / } \\
\text { PROGRAMAS } \\
\text { QUE SE } \\
\text { APLICAM } \\
\text { DIRETAMENTE }\end{array}$ & $\begin{array}{c}\text { QUANTIDADE } \\
\text { TOTAL DE } \\
\text { PROJETOS / } \\
\text { PROGRAMAS } \\
\text { QUE SE APLICAM } \\
\text { INDIRETAMENTE }\end{array}$ & $\begin{array}{l}\text { PROJETOS / } \\
\text { PROGRAMAS }\end{array}$ \\
\hline \multirow{10}{*}{$\begin{array}{l}\text { E } \\
\text { D } \\
\text { U } \\
\text { C } \\
\text { A } \\
\text { C } \\
\text { A } \\
\text { O }\end{array}$} & \multirow{5}{*}{$\begin{array}{l}\text { Ministério } \\
\text { da } \\
\text { Educação } \\
\text { e Cultura }\end{array}$} & \multirow{5}{*}{0} & \multirow{5}{*}{5} & $\begin{array}{c}\text { PDE Escola - Plano } \\
\text { de Desenvolvimento } \\
\text { da Escola }\end{array}$ \\
\hline & & & & $\begin{array}{l}\text { Programa Nacional } \\
\text { de Fortalecimento } \\
\text { dos Conselhos } \\
\text { Escolares }\end{array}$ \\
\hline & & & & $\begin{array}{c}\text { Pro-Conselho - } \\
\text { Programa Nacional } \\
\text { de Capacitação } \\
\text { dos Conselheiros } \\
\text { Municipais } \\
\text { de Educação } \\
\end{array}$ \\
\hline & & & & $\begin{array}{l}\text { Acompanhamento da } \\
\text { Frequência Escolar } \\
\text { de Crianças e Jovens } \\
\text { em Vulnerabilidade } \\
\text { - Condicionalidade } \\
\text { em Educação do } \\
\text { Programa Bolsa } \\
\text { Família - PBF }\end{array}$ \\
\hline & & & & $\begin{array}{l}\text { Projeto Escola Que } \\
\text { Protege }\end{array}$ \\
\hline & $\begin{array}{l}\text { Secretaria } \\
\text { Estadual de } \\
\text { Educação }\end{array}$ & 1 & 0 & $\begin{array}{c}\text { Programa Escola da } \\
\text { Família }\end{array}$ \\
\hline & \multirow{3}{*}{$\begin{array}{l}\text { Secretaria } \\
\text { Municipal } \\
\text { de } \\
\text { Educação }\end{array}$} & \multirow{3}{*}{3} & \multirow{3}{*}{0} & $\begin{array}{c}\text { Programa Minha } \\
\text { Biblioteca }\end{array}$ \\
\hline & & & & $\begin{array}{c}\text { Projeto Recreio nas } \\
\text { Férias/ } \\
\text { Programa } \\
\text { Contraturno Escolar }\end{array}$ \\
\hline & & & & Conviver e aprender \\
\hline & TOTAL & 4 & 5 & \\
\hline
\end{tabular}

Fonte: http://www.mec.gov.br/; http://www.educacao.sp.gov.br/; http://educacao. prefeitura.sp.gov.br/. Acesso em: 23 nov. 2013. Elaboração das autoras. 


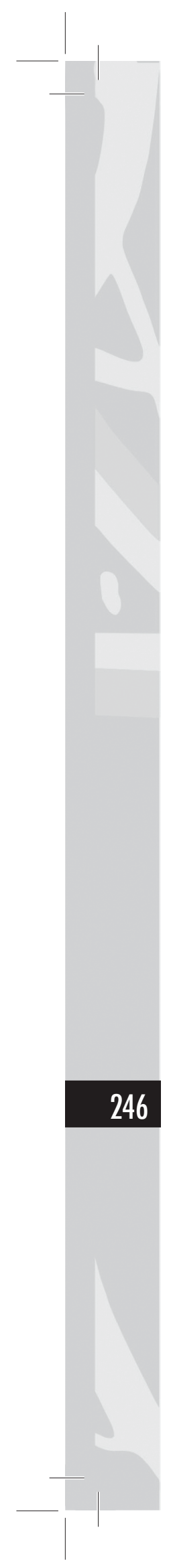

Em nível federal, no Ministério da Educação e Cultura, foram localizados cinco programas/projetos que atenderiam indiretamente o objetivo do PNEDH investigado neste trabalho. Compreende-se que os programas: PDE Escola (Plano de Desenvolvimento da Escola), Programa Nacional de Fortalecimento dos Conselhos Escolares, Pro-Conselho (Programa Nacional de Capacitação dos Conselheiros Municipais de Educação), Acompanhamento da Frequência Escolar de Crianças e Jovens em Vulnerabilidade (Condicionalidade em Educação do Programa Bolsa Família - PBF) e o Escola Que Protege, não se aplicam diretamente, pois dependem de os projetos elaborados dentro de cada uma das escolas envolvidas nos Programas/Projetos terem proposto ação de promoção para interação escola-família. Esse tipo de informação não foi objeto do levantamento realizado, mas suscitou inquietação para o desenvolvimento de outras pesquisas futuras, que demandaria investigação junto às escolas que aderem a esses programas/projetos.

Ao verificarmos os programas/projetos da Secretaria Estadual de Educação do Estado de São Paulo, identificamos apenas o Programa "Escola da Família" como estando relacionado ao objetivo da ação de número 12 do eixo "Educação Básica" do PNEDH. Considerou-se como correspondente ao objetivo, uma vez que as crianças de 6 anos de idade estão sendo matriculadas no $1^{\circ}$ ano do ciclo I do Ensino Fundamental, o qual também é de responsabilidade da rede estadual paulista.

Na Secretaria Municipal de Educação de São Paulo foram três programas/projetos localizados, os quais se aplicaram diretamente ao objetivo. O Programa "Minha Biblioteca", porque aproxima a família da escola por meio do incentivo à leitura pelos filhos e pais (atende crianças do $1^{\circ}$ ano do ciclo I do Ensino Fundamental, as quais estão na faixa etária de 6 anos de idade); o Programa "Contraturno Escolar", uma vez que contempla dois projetos: "Projeto Recreio nas Férias" , o qual tem como propósito ampliar a integração escola comunidade e o "Projeto Conviver e Aprender", que tem como objetivos: "[...] Reafirmar a escola como espaço democrático e de exercício da cidadania no processo de ensino-aprendizagem e contribuir para a melhoria das relações sociais e do exercício 
da convivência e da cooperação no âmbito da rede municipal de ensino" (PREFEITURA DE SÃO PAULO - EDUCAÇÃO. Proposta. Portal da Secretaria Municipal de Educação de São Paulo. Disponível em: <http://portalsme.prefeitura.sp.gov.br/ Projetos/convivereaprender/AnonimoSistema/quemsomos. aspx?MenuID=1>. Acesso em: 23 nov. 2013). Esses programas/ projetos do município de São Paulo têm ações de proteção às crianças, considerando o entorno da escola e caracterizando a comunidade como também responsável pela garantia dos direitos da criança.

2 Programas/projetos na área dos direitos humanos e do desenvolvimento social

A distribuição dos programas/projetos corresponde à área dos Direitos Humanos e do Desenvolvimento Social levantados nos sites oficiais dos governos federal (Secretaria dos Direitos Humanos), estadual (Secretaria do Desenvolvimento Social) e municipal (Secretaria de Assistência e Desenvolvimento Social).

A Tabela 2 a seguir expõe a quantidade de quatro programas/projetos com correspondência indireta ao objetivo da ação de número 12 do eixo Educação Básica do PNEDH. Vejamos.

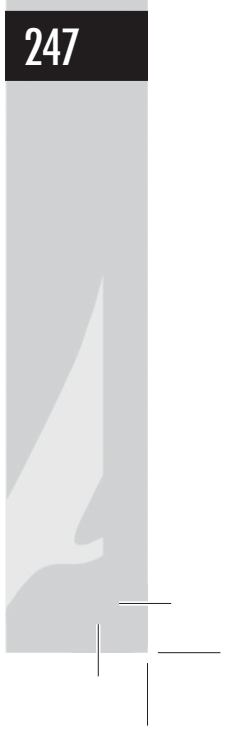


Tabela 2: Programas/projetos na área dos Direitos Humanos e do Desenvolvimento Social

\begin{tabular}{|c|c|c|c|c|}
\hline & & $\begin{array}{l}\text { QUANTIDADE } \\
\text { TOTAL DE } \\
\text { PROJETOS / } \\
\text { PROGRAMAS } \\
\text { QUE SE } \\
\text { APLICAM } \\
\text { DIRETA- } \\
\text { MENTE }\end{array}$ & $\begin{array}{l}\text { QUANTIDADE } \\
\text { TOTAL DE } \\
\text { PROJETOS / } \\
\text { PROGRAMAS } \\
\text { QUE SE } \\
\text { APLICAM } \\
\text { INDIRETA- } \\
\text { MENTE }\end{array}$ & $\begin{array}{c}\text { PROJETOS / } \\
\text { PROGRAMAS }\end{array}$ \\
\hline \multirow{2}{*}{\multicolumn{2}{|c|}{$\begin{array}{l}\text { Secretaria } \\
\text { de Direitos } \\
\text { Humanos } \\
\text { (FEDERAL) }\end{array}$}} & \multirow[t]{2}{*}{0} & \multirow[t]{2}{*}{2} & $\begin{array}{c}\text { Política Nacional } \\
\text { do direito de } \\
\text { crianças e } \\
\text { adolescentes } \\
\text { à Convivência } \\
\text { Familiar e } \\
\text { Comunitária: } \\
\text { Primeira } \\
\text { Infância } \\
\end{array}$ \\
\hline & & & & $\begin{array}{c}\text { Sistema de } \\
\text { Informações } \\
\text { para Infância e } \\
\text { Adolescência - } \\
\text { Sipia }\end{array}$ \\
\hline $\begin{array}{l}\mathrm{E} \\
\mathrm{N} \\
\mathrm{T} \\
\mathrm{O} \\
\mathrm{S} \\
\mathrm{O}\end{array}$ & $\begin{array}{c}\text { Secretaria do } \\
\text { Desenvolvimento } \\
\text { Social } \\
\text { (ESTADUAL) }\end{array}$ & 0 & 0 & $\begin{array}{c}\text { Não foram } \\
\text { localizados } \\
\text { Programas/ } \\
\text { Projetos com } \\
\text { alcance direto ou } \\
\text { indireto. }\end{array}$ \\
\hline $\begin{array}{c}\mathrm{I} \\
\mathrm{A} \\
\mathrm{L} \\
- \\
\mathrm{DH}\end{array}$ & $\begin{array}{c}\text { Secretaria de } \\
\text { Assistência e } \\
\text { Desenvolvimento } \\
\text { Social } \\
\text { (MUNICIPAL) }\end{array}$ & 0 & 2 & $\begin{array}{c}\text { Transferência } \\
\text { de Renda: } \\
\text { Programa Bolsa } \\
\text { Família }\end{array}$ \\
\hline & TOTAL & 0 & 4 & $\begin{array}{l}\text { EDH na rede } \\
\text { municipal de } \\
\text { ensino }\end{array}$ \\
\hline
\end{tabular}

Fonte: http://www.sdh.gov.br/; http://www.desenvolvimentosocial.sp.gov. br/; http://www.prefeitura.sp.gov.br/cidade/secretarias/assistencia_social/. Acesso em 15/03/2014. Elaboração das autoras. 
Na Secretaria de Direitos Humanos, foram localizados os programas: "Política Nacional do direito de crianças e adolescentes à Convivência Familiar e Comunitária: Primeira Infância" que tem como objetivo garantir e promover os direitos básicos de crianças de 0 a 6 anos, por meio do apoio à rede nacional da primeira infância e o "Sistema de Informações para Infância e Adolescência - Sipia”.

O "Sipia" oferece um conjunto de dados consolidados, que podem ser acessados pela internet, são relatórios locais, regionais, estaduais e nacionais para apoiar a construção, o desenvolvimento e o monitoramento de agendas de promoção, proteção e defesa dos direitos humanos de crianças e adolescentes. Com o interesse de fortalecer os processos elaboração, gestão e monitoramento de políticas, planos, programas, projetos e outras iniciativas, fomentando a produção de conhecimento e disseminando informações de interesse público relacionadas à garantia de direitos de crianças e adolescentes. (SECRETARIA DE DIREITOS HUMANOS - PRESIDÊNCIA DA REPÚBLICA. Sistema de Informações para Infância e Adolescência Sipia. Disponivel em: <http://www.sdh.gov.br/assuntos/ criancas-e-adolescentes/programas/convivenciafamiliar-a-comunitaria >. Acesso em: 23 nov. 2013).

A Secretaria do Desenvolvimento Social do Estado de São Paulo não apresentou Programas/Projetos que atendessem direta ou indiretamente o objetivo pesquisado.

$\mathrm{Na}$ Secretaria de Assistência e Desenvolvimento Social do Município de São Paulo há dois programas/projetos: "Transferência de Renda:Programa Bolsa Família" e "Educaçãoem Direitos Humanos", e esse último visa a formação de profissionais para a implementação de uma Educação em Direitos Humanos (EDH) na rede municipal de educação. Consideramos estes programas/projetos com objetivos que se aproximam de ações que promovem experiências de interação escola-comunidade, 


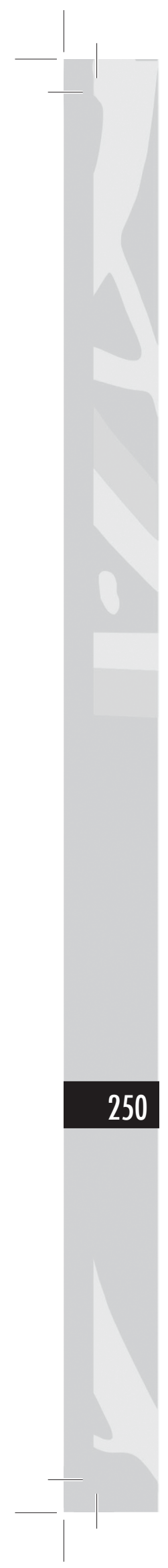

embora não proponham ações diretas de aproximação da família na escola. Consideramos que esses programas/projetos se relacionam com propostas de fortalecimento da promoção do desenvolvimento integral de crianças de 0 a 6 anos, uma vez que o Programa Bolsa Família cria condições para que as famílias em situação de vulnerabilidade social possam manter seus filhos estudando, e o EDH na rede municipal de ensino oferece formação aos professores para que desenvolvam práticas docentes fundamentadas na perspectiva de uma Educação em Direitos Humanos.

\section{Considerações finais}

Do total de 13 programas/projetos levantados em sites oficiais dos governos federal, do estado de São Paulo e do município de São Paulo, nove são da Educação e quatro são da área de Direitos Humanos e Desenvolvimento Social, e nessa última em nenhuma das ações foi possível estabelecer uma correspondência direta de alcance com o objetivo investigado, qual seja: programa/projeto que visasse apoiar a implementação de experiências de interação da escola com a comunidade.

$\mathrm{Na}$ área da Educação, cinco programas/projetos do Ministério da Educação e Cultura (MEC) foram identificados como tendo alcance indireto e quatro foram considerados correspondentes ao objetivo, sendo três deles da Secretaria Municipal de Educação de São Paulo e um da Secretaria Estadual de Educação de São Paulo.

$\mathrm{Na}$ área dos Direitos Humanos e do Desenvolvimento Social, todos os quatro programas/projetos encontrados apresentam objetivos que permitiram ser identificados com alcance indireto em relação ao objetivo da pesquisa. Ao serem somados esses quatro com os cinco da área da Educação, temos um total de nove, o que representa praticamente um pouco mais que o dobro do número total de programas/projetos com aplicação direta (quatro). Além disso, os programas/projetos propostos pelos órgãos do governo federal dependem da adesão das escolas que pertencem às redes estadual e municipal 
de ensino ou mesmo das respectivas secretarias e/ou ainda das secretarias de Desenvolvimento Social para intermediação da ação de implementação.

O fato de os sites não disponibilizarem dados a respeito das metas, resultados esperados e alcançados dificulta o cruzamento de informações para a realização de análises de natureza qualitativa. Pelo conteúdo dos objetivos dos programas/projetos identificados com aplicação considerada direta ao objetivo investigado, pode-se afirmar que há intencionalidade em promover interação escola-comunidade, embora a maioria deles não explicite essa intenção como sendo a única e tampouco se estabeleça relação com a ação de número 12 do eixo "Educação Básica" do Plano Nacional de Educação em Direitos Humanos.

O que se constata é que há um número pouco expressivo de Programas/Projetos nos governos federal, paulista e paulistano com o propósito de apoiar a implementação de experiências da escola com a comunidade, especialmente nas escolas de Educação Infantil.

\section{REFERÊNCIAS}

BRASIL. Constituição (1988). Constituição da República Federativa do Brasil. Brasília, DF: Senado Federal, 1988.

BRASIL. Lei 8.069, de 13 de julho de 1990. Dispõe sobre o Estatuto da Criança e do Adolescente e dá outras Providências. Disponível em: http://www.planalto.gov.br/ccivil_03/leis/18069.htm. Acesso em: 23 de nov. 2013.

BRASIL. Lei 9.394, de 20 de dezembro de 1996. Estabelece as Diretrizes e Bases da Educação Nacional. Diário Oficial [da República Federativa do Brasil]. Brasília, DF, v. 134, n. 248, p. 01-32, 23 dez. 1996. 
BRASIL. Ministério da Justiça. Secretaria Especial dos Direitos Humanos. Ministério da Educação. Comitê de Educação em Direitos Humanos. Plano Nacional de Educação em Direitos Humanos. Brasília, DF: MEC/MJ/Unesco, 2009.

ORGANIZAÇÃO DAS NAÇÕES UNIDAS (ONU). Declaração Universal dos Direitos Humanos. Adotada e proclamada pela resolução 217 A (III) da Assembleia Geral das Nações Unidas em 10 de dezembro de 1948. Disponível em: Biblioteca Virtual de Direitos Humanos da Universidade de São Paulo: www.direitoshumanos.usp. br. Acesso em: 23 de nov. de 2013.

ORGANIZAÇÃO DAS NAÇÕES UNIDAS (ONU). CONFERÊNCIA MUNDIAL SOBRE OS DIREITOS DO HOMEM. Viena, 14-25 de Junho de 1993. Disponível em: http:// www.dhnet.org.br/direitos/anthist/viena/viena.html. Acesso em: 23 de nov. 2013.

PIOVESAN, Flávia. Direitos Humanos: desafios da ordem internacional contemporânea. In: MARTINS, José R.; SOUSA, Nair H. B. de; LEFÉVRE, Júlia M. Educação para a paz e Direitos Humanos. Brasília, DF: Secretaria Geral da Presidência da República, 2008. p. 219-244.

PREFEITURA DE SÃO PAULO - EDUCAÇÃO. Proposta. Portal da Secretaria Municipal de Educação de São Paulo. Disponível em: $<$ http://portalsme.prefeitura.sp.gov.br/Projetos/convivereaprender/ AnonimoSistema/quemsomos.aspx?MenuID=1>. Acesso em: 23 nov. 2013.

SECRETARIA DE DIREITOS HUMANOS - PRESIDÊNCIA DA REPÚBLICA. Política Nacional do direito de crianças e adolescentes à Convivência Familiar e Comunitária. Disponível em: $\quad$ http://www.sdh.gov.br/assuntos/criancas-e-adolescentes/ programas/convivencia-familiar-a-comunitaria $>$. Acesso em: 23 nov. 2013 
SECRETARIA DE DIREITOS HUMANOS - PRESIDÊNCIA DA REPÚBLICA. Sistema de Informações para Infância e Adolescência - Sipia. Disponível em: <http://www.sdh.gov.br/ assuntos/criancas-e-adolescentes/programas/convivencia-familiara-comunitaria>. Acesso em: 23 nov. 2013.

VIOLA, Solon E. A. Políticas de Educação em Direitos Humanos. In: SILVA, Aida Maria Monteiro; TAVARES, Celma (Org.). Políticas e fundamentos da educação em direitos humanos. São Paulo: Cortez, 2010. p. 15-40.

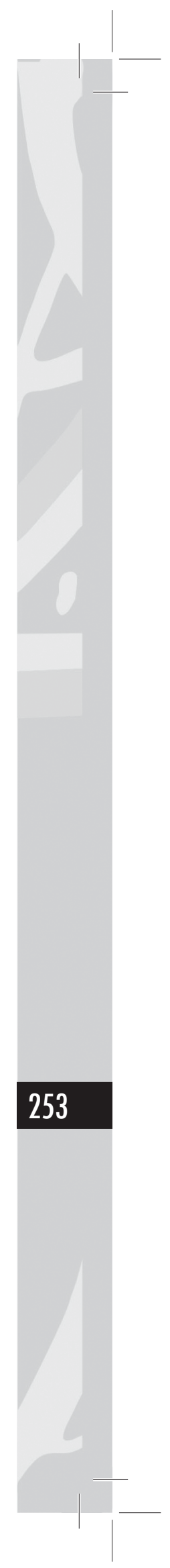

